Research Paper

\title{
Increased serum levels of betatrophin in pancreatic cancer- associated diabetes
}

\author{
Hendra Susanto ${ }^{1, *}$, Ta-Yu Liu ${ }^{1, *}$, Chang-Chiang Chen ${ }^{1,2, *}$, Jerry D.T. Purnomo ${ }^{3}$, Shu-Fan \\ Chen ${ }^{1}$, Chih-Hong Wang ${ }^{1}$ \\ ${ }^{1}$ Department of Biological Science and Technology, National Chiao Tung University, Hsinchu 300, Taiwan \\ ${ }^{2}$ Department of Internal Medicine, National Taiwan University Hospital Hsin-Chu Branch, Hsinchu 300, Taiwan \\ ${ }^{3}$ Institute of Statistics, National Chiao Tung University, Hsinchu 300, Taiwan \\ * These authors have contributed equally to this work \\ Correspondence to: Chih-Hong Wang, email: chihhong@nctu.edu.tw \\ Keywords: betatrophin, diabetes, insulin resistance, glucose intolerance, pancreatic cancer \\ Received: December 13,2015 Accepted: May 20, $2016 \quad$ Published: June 3, 2016
}

\section{ABSTRACT}

Long-standing diabetes or glucose intolerance is recognized as a crucial event in the process of pancreatic cancer. Betatrophin, a novel liver-derived hormone, promotes $\beta$-cell proliferation and improves glucose intolerance. However, the relationship between betatrophin and PDAC-associated diabetes is not fully understood. To evaluate the serum betatrophin levels in PDAC-associated diabetes, a total 105 Taiwanese subjects including 15 healthy subjects, and 12 patients having PDAC with normal glucose tolerance (PDAC-NGT), 12 patients having PC with impaired glucose tolerance (PDAC-IGT), and 66 patients having PC with diabetes mellitus (PDAC-DM) were enrolled for this study. Serum betatrophin and carbohydrate antigen 19-9 (CA19-9) levels were analyzed by enzyme-linked immunosorbent assay (ELISA). Compared to healthy subjects, PDAC patients had higher levels of betatrophin and CA19-9. Consistently, betatrophin protein was significantly expressed in pancreatic ductal of PDAC-associated DM patients using immunohistochemistry (IHC) method. Furthermore, multivariate regression analysis showed the betatrophin was significantly and positively independent with $T$ category $(\beta=0.605, P=0.010)$, serum albumin $(\beta=0.423, P=0.021)$, lipase $(\beta=0.292, P=0.039)$, and blood urea nitrogen ( $B U N)(\beta=0.303, P=0.040)$. Further, the betatrophin was three folds of having PDAC-associated diabetes with the highest odds ratio [OR $=3.39 ; 95 \% \mathrm{CI}$ (1.20-9.57); $P=0.021)$ and receiver operating characteristic $(R O C)$ curve analysis showed that AUC value of betarophin was 0.853 which is slightly larger than AUC value of CA19-9 (0.792) in PDAC-DM patients. Interestingly, AUC value of betarophin plus CA19-9 was 0.988 in PDAC-DM patients. Therefore, betatrophin combined CA19-9 may serve as a potential biomarker for PDAC-associated diabetes.

\section{INTRODUCTION}

Pancreatic ductal adenocarcinoma (PDAC), one of the most aggressive human cancers, is the fourth leading cause of cancer-related deaths in the United States [1]. The incidence and mortality rates of PDAC are similar, with the 5-year survival rate of $\sim 5 \%[2,3]$. Most PDAC patients are diagnosed at an advanced stages, and only $10 \%$ to $20 \%$ of patients are resectable at the time of presentation [4]. Based on human epidemiologic and animal studies, most PDAC patients have glucose intolerance [5] and about
$80 \%$ of PDAC patients are either glycemic or diabetic and this exists in the pre-symptomatic phase [6]. PDACassociated diabetes can occur at a resectable stage, while resection of pancreatic tumor improves glucose intolerance [7]. Therefore, discovery of novel biomarkers for PDACassociated diabetes may apply for diagnosis of resectable PDAC at early stages.

Dysfunctions of $\beta$-cell and insulin resistance are often seen in PDAC. Recently, betatrophin, a newly recognized liver-derived hormone, has been implicated in glucose metabolism and $\beta$-cell proliferation [8]. It significantly and 
specifically promotes pancreatic $\beta$-cell proliferation and improves glucose intolerance in mouse models of insulin resistance [9]. These results suggest betatrophin to be a liver-derived protein that triggers compensatory $\beta$-cell proliferation upon insulin resistance [9]. Further, serum levels of betatrophin are positively associated with type 1 diabetes mellitus (T1DM), type 2 diabetes mellitus (T2DM) [10-12], hyperlipidemia [13], and indexes of insulin resistance [14]. Nevertheless, it is unclear whether serum betatrophin levels are correlated with PDAC-associated diabetes and whether serum betarophin levels can serve as a biomarker for PDAC-associated diabetes to apply for diagnosis of resectable PDAC.

The aim of this study is to investigate the relationship between serum betatrophin concentrations and PDAC with or without glucose intolerance, and to determine whether betatrophin levels can serve as a biomarker for PDAC-associated diabetes. We investigated serum betatrophin levels in healthy subjects and PDAC patients with various stages of glucose tolerance: normal glucose tolerance (NGT), impaired glucose tolerance (IGT), and diabetes mellitus (DM). We hypothesized that betatrophin is correlated with PDAC-associated diabetes and can serve as biomarker to predict PDAC-associated diabetes for surgical resection of tumor.

\section{RESULTS}

\section{Baseline characteristics of the total study participants}

Table 1 summarizes the clinical baseline characteristics of the four groups (healthy control, PDAC-NGT, PDAC-IGT, and PDAC-DM). Compared with healthy control subjects, the serum levels of triglyceride, albumin, alkaline phosphatase (ALP), alanine aminotransferase (ALT), aspartate aminotransferase (AST), amylase, lipase, and blood urea nitrogen (BUN) were significantly increased in PDAC-NGT, PDAC-IGT and PDAC-DM patients, while the hemoglobin and hematocrit (Hct) were significantly decreased. In addition, plasma levels of insulin were significantly increased in PDACDM patients. No statistically significant was found in sex and age between healthy controls and PDAC groups. Interestingly, PDAC patients had higher levels of the betatrophin than healthy control subjects. The betatrophin levels from lowest to highest were healthy subjects, PDACDM, PDAC-IGT and PDAC-NGT (Table 1 and Figure 1A). Consistently, betatrophin protein was significantly expressed in pancreatic ductal of PC-associated DM patients using immunohistochemistry (IHC) method (Figure 2). These data suggest that higher glucose levels may affect betatrophin expression from liver and adipose tissue in PDAC patients.

Moreover, serum carbohydrate antigen 19-9 (CA19-

9) is commonly used biomarker in pancreatic cancer [15].
We found that CA19-9 was significantly increased in PDAC-DM patients as compared with healthy subjects (Table 1 and Figure 1B). Therefore, both serum levels of betatrophin and CA19-9 were significantly increased in PDAC-DM patients.

\section{Univariate correlations in the total sample}

The serum betatrophin levels were found to be positively correlated with albumin, amylase, lipase, BUN, and $\mathrm{T}$ category $(\mathrm{P}<0.05$; Table 2$)$, while its levels were inversely correlated with cholesterol, hemoglobin, and Hct ( $\mathrm{P}<0.05$; Table 2). Interestingly, although betatrophin was not correlated with fasting blood glucose (FBG) in all subjects, it was significantly associated with PDAC patients with various stages of glucose tolerance (PDACNGT $[r=-0.589 ; \mathrm{P}=0.015] ;$ PDAC-IGT $[r=-0.554$; $\mathrm{P}=0.017]$; PDAC-DM $[r=-0.586 ; \mathrm{P}=0.002]$, respectively).

\section{Multivariate regression analysis in the total sample}

To verify independent associations, multiple linear regression analysis was performed. Here, T category of PDAC was a positive, independent and significant predictor of serum betatrophin levels $(\beta=0.605, \mathrm{P}=0.010$; Table 3). Furthermore, the serum CA19-9 $(\beta=0$. 001, $\mathrm{P}=0.047)$, albumin $(\beta=0.423, \mathrm{P}=0.021)$, lipase $(\beta=0.292, \mathrm{P}=0.039)$, and $\mathrm{BUN}(\beta=0.303, \mathrm{P}=0.040)$ were also significantly and positively associated with serum betatrophin levels (Table 3 ).

\section{Association between serum betatrophin levels and PDAC patients with various stages of glucose tolerance}

We used the ordinal logistic regression analysis to estimated associations between serum betatrophin levels and PDAC patients with various stages of glucose tolerance (NGT: FBG < 99 mg/dL. IGT: FBG between $100 \mathrm{mg} / \mathrm{dL}$ and $125 \mathrm{mg} / \mathrm{dL}$. DM: FBG >126 mg/dL). We found that betatrophin $[\mathrm{OR}=3.39,95 \% \mathrm{CI}(1.20-$ 9.57), $\mathrm{P}=0.021]$ was higher than $\mathrm{CA} 19-9[\mathrm{OR}=1.00$, $95 \%$ CI (0.09-1.01), $\mathrm{P}=0.295]$, amylase $[\mathrm{OR}=1.01$, $95 \%$ CI (1.00-1.02), $\mathrm{P}=0.002]$, and lipase $[\mathrm{OR}=1.01$, 95\% CI (1.00-1.01), $\mathrm{P}=0.151]$ (Table 4). Moreover, we used receiver operating characteristic (ROC) analysis to assess the potential benefit of using betatrophin instead of CA19-9. When we compared the area under the curve (AUC) value of each biomarker, the sensitivity and specificity of betatrophin was significantly higher than CA 19-9 (Figure 3). AUC value of betatrophin in PDACDM patients (0.853) was higher than PDAC-IGT (0.668) and PDAC-NGT (0.694), while AUC value of CA19-9 in PDAC-DM patients (0.792) was higher than PDACIGT (0.530) and PDAC-NGT (0.479). Interestingly, 
Table 1: Baseline characteristics of the study population

\begin{tabular}{|c|c|c|c|c|}
\hline & Healthy & PDAC-NGT & PDAC-IGT & PDAC-DM \\
\hline $\mathrm{N}$ & 15 & 12 & 12 & 66 \\
\hline Age (years) & $66.80 \pm 1.43$ & $65.87 \pm 2.62$ & $67.27 \pm 2.44$ & $67.59 \pm 0.97$ \\
\hline$\%$ of male & 67 & 67 & 58 & 70 \\
\hline $\mathrm{FBG}(\mathrm{mg} / \mathrm{dL})$ & $101.80 \pm 4.78$ & $75.93 \pm 6.08 *$ & $111.38 \pm 2.46^{\dagger}$ & $205.49 \pm 6.39^{* \dagger *}$ \\
\hline Cholesterol (mg/dL) & $180.33 \pm 11.55$ & $104.83 \pm 8.43^{*}$ & $108.45 \pm 5.11^{*}$ & $106.15 \pm 3.48^{*}$ \\
\hline Triglyceride (mg/dlL) & $100.93 \pm 16.94$ & $161.41 \pm 13.32 *$ & $191.92 \pm 15.19 *$ & $181.46 \pm 7.86^{*}$ \\
\hline Hemoglobin (\%) & $14.45 \pm 0.48$ & $11.17 \pm 0.59^{*}$ & $12.80 \pm 0.34 *$ & $12.13 \pm 0.17 *$ \\
\hline Albumin (g/dL) & $4.87 \pm 0.23$ & $3.26 \pm 0.20 *$ & $3.87 \pm 0.12 *$ & $3.61 \pm 0.07^{*}$ \\
\hline ALP (U/L) & $107.53 \pm 23.86$ & $297.95 \pm 69.99 *$ & $236.16 \pm 51.04 *$ & $315.55 \pm 24.77 *$ \\
\hline $\operatorname{ALT}(\mathrm{U} / \mathrm{L})$ & $9.80 \pm 1.80$ & $106.00 \pm 25.84 *$ & $181.83 \pm 32.54^{* \dagger}$ & $190.55 \pm 23.64^{* \dagger}$ \\
\hline AST (U/L) & $9.15 \pm 1.44$ & $81.77 \pm 10.42^{*}$ & $66.72 \pm 18.98^{*}$ & $153.24 \pm 17.48^{* \dagger}$ \\
\hline Amylase (U/L) & $28.67 \pm 2.15$ & $269.33 \pm 116.31 *$ & $176.22 \pm 68.62 *$ & $263.00 \pm 57.22^{*}$ \\
\hline Lipase (U/L) & $20.73 \pm 1.80$ & $817.71 \pm 532.71 *$ & $499.80 \pm 231.88^{*}$ & $532.72 \pm 83.68^{*}$ \\
\hline Survival (years) & & $1.53 \pm 0.32$ & $0.58 \pm 0.11 *$ & $0.46 \pm 0.17^{*}$ \\
\hline Hct $(\%)$ & $45.85 \pm 3.57$ & $27.16 \pm 5.34^{*}$ & $29.05 \pm 4.01 *$ & $32.12 \pm 1.39^{* \dagger}$ \\
\hline BUN (mg/dL) & $4.24 \pm 0.62$ & $14.78 \pm 2.64$ & $15.33 \pm 1.19$ & $15.72 \pm 0.89$ \\
\hline Creatinitne $(\mu \mathrm{mol} / \mathrm{L})$ & $79.12 \pm 12.05$ & $82.54 \pm 13.15$ & $95.45 \pm 9.29$ & $87.82 \pm 15.34$ \\
\hline $\begin{array}{l}\text { T category (I\&II : } \\
\text { III\&IV) }\end{array}$ & & $8: 4$ & $6: 6$ & $38: 28$ \\
\hline $\mathrm{N}$ category $(\mathrm{N} 0: \mathrm{N} 1)$ & & $2: 10$ & $7: 5$ & $42: 24$ \\
\hline insulin (mU/L) & $2.25 \pm 0.41$ & $2.45 \pm 0.77$ & $4.08 \pm 1.57$ & $5.48 \pm 0.63^{*}$ \\
\hline CA 19-9 (U/mL) & $9.39 \pm 2.75$ & $67.09 \pm 36.53$ & $88.94 \pm 29.02$ & $88.54 \pm 16.19 *$ \\
\hline betatrophin (pg/mL) & $702.51 \pm 112.78$ & $1398.13 \pm 157.07 *$ & $1315.77 \pm 119.54^{* \dagger}$ & $1205.79 \pm 44.44^{* * *}$ \\
\hline
\end{tabular}

Abbreviations: FBG: Fasting Blood Glucose; ALP: Alkaline Phosphatase; ALT: Alanine Aminotransferase; AST: Aspartate Aminotransferase; Hct: hematocrit; BUN: blood urea nitrogen. Normal Glucose Tolerance (NGT) $[\leq 99$ mg/dL (5.5. $\mathrm{mmol} / \mathrm{L})]$, Impaired Glucose Tolerance (IGT) [100-125 mg/dl (5.6-6.9 mmol/L)], Diabetes Mellitus (DM) [ $\geq 126 \mathrm{mg} / \mathrm{dl}$ $(7 \mathrm{mmol} / \mathrm{L})]$. Data are means $\pm \mathrm{SD} .{ }^{*}, \mathrm{P}<0.05$ vs. healthy subjects; ${ }^{\dagger}, \mathrm{P}<0.05$ vs. PaC-NGT; ${ }^{\ddagger}, \mathrm{P}<0.05$ vs. PaC-IGT. TNM classification is according to the International Union against Cancer (UICC, 2002).

betatrophin combined CA 19-9 showed a significant predict PDAC-associated diabetes and AUC value of betatrophin combined CA19-9 in PDAC-DM (0.9877) was higher than in PDAC-IGT (0.639), and PDAC-NGT (0.643) (Figure 3). Therefore, the betatrophin combined CA19-9 may serve as a potential biomarker for PDACassociated diabetes.

\section{DISCUSSION}

PDAC is the fourth most common cause of death from cancer in the western world, and long-term survival remains poor with a 5-year survival rate less 5\% [16].
Resection is associated with improved survival but this is only possible in approximately $10 \%$ of patients [7]. PDAC patients often have impaired glucose tolerance or diabetes at early stage, while surgical resection of the tumor improves glucose tolerance and insulin resistance $[7,17]$. The development of PDAC-DM is a promising clue for the early detection of pancreatic cancer, but how PDAC causes diabetes is largely unknown. We analyzed that serum betatrophin levels in patients with PDAC-NGT, PDAC-IGT, and PDAC-DM as well as healthy subjects as control. Our data indicated that betatrophin levels not only predicted PDAC-DM, but also served as biomarker for tumor stages in PDAC. 
The pathogenesis of PDAC-associated diabetes and its biochemical mediators are not known. This is unlikely to be simply due to destruction of the gland by the tumor. The high prevalence of glucose intolerance or diabetes occurs at early stage of PDAC and the tumor size is smaller than $2 \mathrm{~cm}$ that provide an ideal clue for resection of tumors to increase survival [18]. However, PDAC-DM cannot be easily identified from other types of diabetes by clinical signs and symptoms, and specific markers are urgently needed [19]. Several factors related to PDAC-DM have been identified, such as insulin and C-peptide [6, 20, 21]. Insulin and $\mathrm{C}$-peptide levels in diabetes are higher than in healthy controls, while low levels of insulin and C-peptide are seen in PDAC-associated diabetes [22]. This discrepancy could be simply due to decrease of pancreatic $\beta$-cell mass in PDAC-associated diabetes. However, Michaud et al. studies showed that fasting insulin and C-peptide were not related to PDAC, while they observed a slight linear association for nonfasting $\mathrm{C}$-peptide and PDAC [22]. Therefore, the role of insulin and C-peptide levels and other factors in the early diagnosis of PDAC-DM remains unclear.

Recently, betatrophin has been recognized as a novel hormone from liver and adipose tissue, and promotor of $\beta$-cell mass proliferation and improved glucose intolerance in mouse models of insulin resistance $[8,9]$. Circulating betatrophin levels have been reported to correlate with T1D [11] and T2D [23]. Further, betatrophin is also called hepatocellular carcinoma (HCC)-associated Gene TD26, which is highly expressed in HCC $[24,25]$. Several studies have shown that liver and pancreas arise from a common multipotent population of endoderm and exogenous glucocorticoid can cause the
A

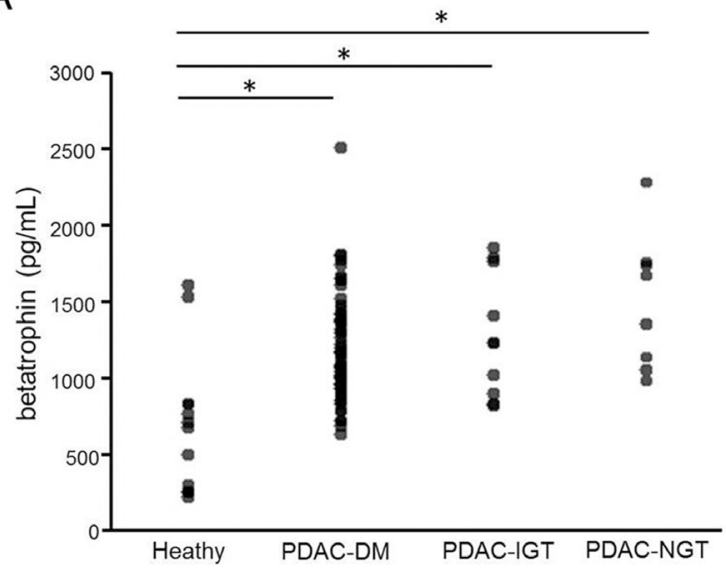

B

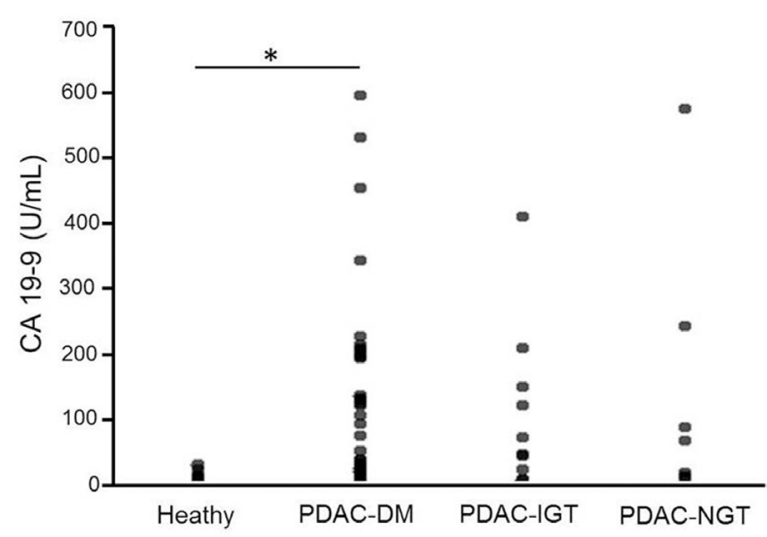

Figure 1: Serum betatrophin and CA19-9 concentrations of healthy and PDAC patients with NGT, IGT, and DM. Normal Glucose Tolerance (NGT) $[\leq 99 \mathrm{mg} / \mathrm{dL}$ (5.5. mmol/L)], Impaired Glucose Tolerance (IGT) [100-125 mg/dl (5.6-6.9 mmol/L)], Diabetes Mellitus (DM) $[\geq 126 \mathrm{mg} / \mathrm{dl}(7 \mathrm{mmol} / \mathrm{L})]$. Data are means $\pm \mathrm{SD}$. *, $\mathrm{P}<0.05$ vs. healthy subjects.
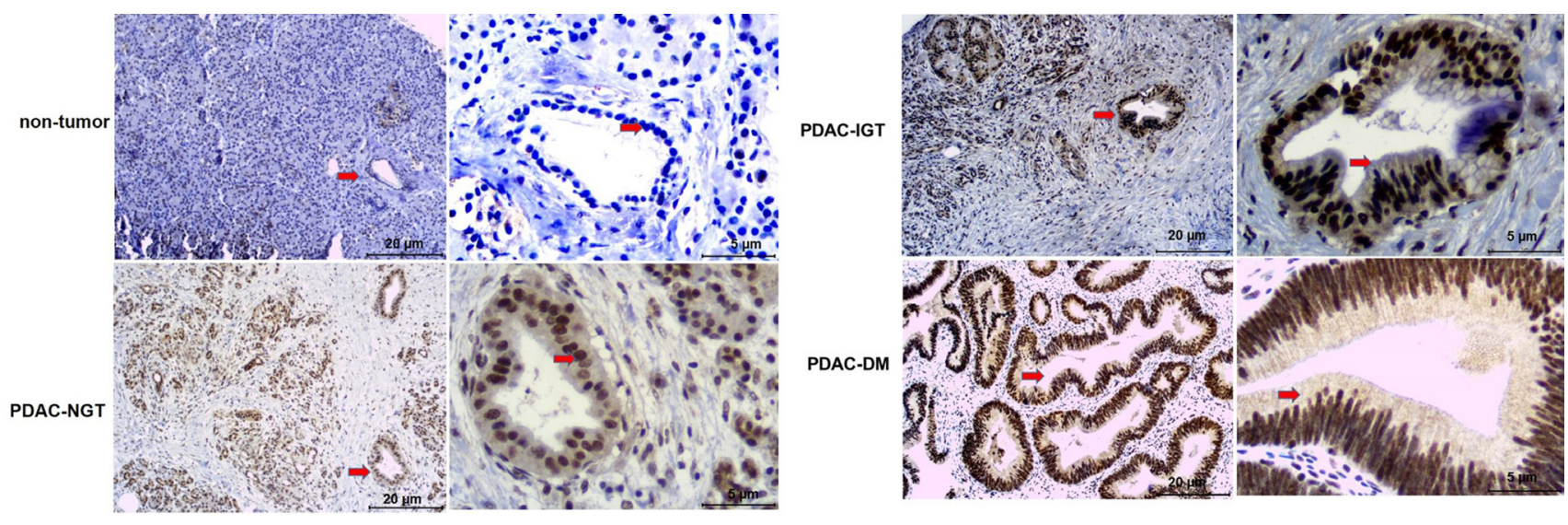

Figure 2: Betatrophin protein expression in human pancreatic cancer cells using immunohistochemical staining. Immunohistochemical staining did not show immunoreactivity in the normal pancreas, whereas there was strong immunoreactivity in the pancreatic ductal of pancreatic cancer cells (arrows) in PDAC-NGT, IGT, and DM. 
Table 2: Univariate correlation with serum betatrophin levels in all participants, healthy, PDAC with NGT, IGT, and DM groups

\begin{tabular}{|c|c|c|c|c|c|c|c|c|c|c|}
\hline & \multicolumn{2}{|c|}{ All subjects } & \multicolumn{2}{|c|}{ Healthy } & \multicolumn{2}{|c|}{ PDAC-NGT } & \multicolumn{2}{|c|}{ PDAC-IGT } & \multicolumn{2}{|c|}{ PDAC-DM } \\
\hline & $r$ & $\boldsymbol{P}$ & $r$ & $P$ & $r$ & $P$ & $r$ & $P$ & $r$ & $\boldsymbol{P}$ \\
\hline $\mathrm{FBG}(\mathrm{mg} / \mathrm{dL})$ & -0.091 & 0.380 & -0.010 & 0.971 & -0.589 & $0.015^{*}$ & -0.554 & $0.017 *$ & -0.586 & $0.002 *$ \\
\hline Cholesterol (mg/dL) & -0.358 & $<0.001 *$ & 0.112 & 0.692 & 0.408 & $0.031 *$ & 0.548 & $0.018^{*}$ & -0.309 & $0.015^{*}$ \\
\hline Triglyceride (mg/dlL) & 0.131 & 0.207 & -0.086 & 0.761 & 0.621 & $0.010^{*}$ & 0.145 & 0.671 & -0.172 & 0.186 \\
\hline Hemoglobin $(\%)$ & -0.205 & $0.046 *$ & -0.088 & 0.755 & 0.299 & 0.472 & 0.243 & 0.472 & 0.019 & 0.882 \\
\hline Albumin (g/dL) & 0.321 & $0.002 *$ & 0.320 & 0.244 & -0.264 & 0.075 & 0.388 & $0.048 *$ & -0.299 & $0.044 *$ \\
\hline $\operatorname{ALP}(\mathrm{U} / \mathrm{L})$ & 0.122 & 0.243 & -0.195 & 0.486 & $0.025^{*}$ & $0.028 *$ & -0.111 & 0.744 & -0.171 & 0.190 \\
\hline $\operatorname{ALT}(\mathrm{U} / \mathrm{L})$ & 0.026 & 0.800 & 0.236 & 0.396 & -0.418 & $0.034 *$ & 0.107 & 0.755 & -0.172 & 0.186 \\
\hline $\operatorname{AST}(\mathrm{U} / \mathrm{L})$ & -0.065 & 0.535 & 0.111 & 0.694 & 0.048 & 0.910 & -0.211 & 0.558 & -0.297 & $0.020 *$ \\
\hline Amylase (U/L) & 0.228 & $0.045^{*}$ & 0.092 & 0.745 & 0.623 & $0.002 *$ & 0.292 & $0.045^{*}$ & 0.112 & 0.439 \\
\hline Lipase $(\mathrm{U} / \mathrm{L})$ & 0.441 & $<0.001 *$ & 0.019 & 0.947 & 0.390 & $0.049 *$ & 0.680 & $0.004 *$ & 0.350 & $0.011 *$ \\
\hline $\operatorname{Hct}(\%)$ & -0.270 & $0.010^{*}$ & 0.336 & 0.220 & 0.370 & 0.058 & 0.830 & $0.003 *$ & 0.155 & 0.242 \\
\hline BUN (mg/dL) & 0.310 & $0.002 *$ & 0.122 & 0.665 & 0.254 & 0.089 & 0.130 & 0.704 & -0.016 & 0.905 \\
\hline Creatinine $(\mu \mathrm{mol} / \mathrm{L})$ & 0.162 & 0.118 & -0.350 & 0.201 & 0.447 & $0.045^{*}$ & 0.310 & 0.075 & 0.165 & 0.203 \\
\hline T category & 0.423 & $<0.001 *$ & - & - & 0.689 & $0.005^{*}$ & 0.351 & $0.050 *$ & 0.154 & 0.237 \\
\hline $\mathrm{N}$ category & 0.198 & 0.083 & - & - & 0.333 & 0.071 & 0.245 & 0.122 & 0.196 & 0.133 \\
\hline
\end{tabular}

Abbreviations: FBG: Fasting Blood Glucose; ALP: Alkaline Phosphatase; ALT: Alanine Aminotransferase; AST: Aspartate Aminotransferase; Hct: hematocrit; BUN: blood urea nitrogen. Normal Glucose Tolerance (NGT) $[\leq 99 \mathrm{mg} / \mathrm{dL}$ (5.5. $\mathrm{mmol} / \mathrm{L})]$, Impaired Glucose Tolerance (IGT) [100-125 mg/dl (5.6-6.9 mmol/L)], Diabetes Mellitus (DM) [ $\geq 126 \mathrm{mg} / \mathrm{dl}$ $(7 \mathrm{mmol} / \mathrm{L})] .{ }^{*}, \mathrm{p}<0.05$ is considered significant. TNM classification is according to the International Union against Cancer (UICC, 2002). Correlations were estimated by spearman correction test.

conversion of pancreatic exocrine cells into hepatocytes [26-28]. We therefore hypothesized that betatrophin is correlated with PDAC-associated diabetes and can serve as biomarker to predict PDAC-associated diabetes for surgical resection of tumor. In the present study, we observed that serum betatrophin levels were significantly increased in PDAC-NGT, PDAC-IGT, and PDAC-DM patients as compared with healthy subjects. This may be caused by decrease of pancreatic $\beta$-cell mass in PDAC patients, which in turn cause increased betatrophin expression to promote $\beta$-cell mass proliferation. However, although serum betatrophin levels were higher in PDAC patients than in healthy subjects, its levels in PDACassociated glucose intolerance or diabetes were lower than in PDAC patients with normal glucose tolerance. It has been known that betatrophin is not only produced by liver, but also is secreted by adipose tissue [29]. The possibility is that elevated serum betatrophin levels is due to cancer-induced anorexia at advanced stages. The early stages of PDAC appear PDAC-associated glucose intolerance or diabetes. Indeed, Barja-Fernández et al. studies have demonstrated that circulating betatrophin levels were significantly elevated in anorexic patients, whereas its levels were reduced in morbidly obese women [29]. However, future studies are needed to investigate this speculation.

Furthermore, we also demonstrated that betatrophin was strongly associated with PDAC-associated diabetes. The betatrophin was three folds of having PDACassociated diabetes with the highest odds ratio $[\mathrm{OR}=3.39$; 95\% CI (1.20-9.57); $\mathrm{P}=0.021)$. The ROC analysis showed that AUC value of betarophin was 0.853. Serum carbohydrate antigen 19-9 (CA19-9) is commonly used biomarker in pancreatic cancer [15]. However, the precise knowledge of CA19-9 in pancreatic cancer diagnosis, staging, determining resectability, response to chemotherapy and prognosis remains limited. In our study, we also measured CA19-9, and found that the AUC value of CA 19-9 in PDAC-DM was 0.792 that is lower than that of betatrophin. Interestingly, AUC value of betatrophin combined CA19-9 was 0.988 in PDACDM patients. Therefore, betatrophin combined CA19-9 may serve as a potential biomarker for PDAC-associated diabetes. 
Table 3: Univariate correlations and multivariate regression analysis with serum betatrophin levels

\begin{tabular}{|c|c|c|c|c|}
\hline \multirow{2}{*}{$\begin{array}{l}\text { Independent } \\
\text { Variables }\end{array}$} & \multicolumn{2}{|c|}{ Univariate analysis } & \multicolumn{2}{|c|}{ Multivariate analysis } \\
\hline & $r$ & $P$ & $\beta$ & $P$ \\
\hline FBG (mg/dL) & -0.091 & 0.380 & & \\
\hline CA19-9 & 0.386 & $0.001 *$ & 0.001 & 0.047 \\
\hline Cholesterol (mg/dL) & -0.358 & $<0.001^{*}$ & -0.103 & 0.475 \\
\hline Triglyceride (mg/dlL) & 0.131 & 0.207 & & \\
\hline Hemoglobin (\%) & -0.205 & $0.046^{*}$ & -0.084 & 0.567 \\
\hline Albumin (g/dL) & 0.321 & $0.002 *$ & 0.423 & $0.021 *$ \\
\hline $\mathrm{ALP}(\mathrm{U} / \mathrm{L})$ & 0.122 & 0.243 & & \\
\hline $\operatorname{ALT}(\mathrm{U} / \mathrm{L})$ & 0.026 & 0.800 & & \\
\hline AST (U/L) & -0.065 & 0.535 & & \\
\hline Amylase (U/L) & 0.228 & $0.045^{*}$ & 0.084 & 0.465 \\
\hline Lipase (U/L) & 0.441 & $<0.001^{*}$ & 0.292 & $0.039 *$ \\
\hline Survival (years) & 0.114 & 0.256 & & \\
\hline Hct $(\%)$ & -0.270 & $0.010^{*}$ & 0.319 & 0.150 \\
\hline BUN (mg/dL) & 0.310 & $0.002 *$ & 0.303 & $0.040^{*}$ \\
\hline Creatinine (umol/L) & 0.162 & 0.118 & & \\
\hline $\mathrm{T}$ category & 0.423 & $<0.001 *$ & 0.605 & $0.010^{*}$ \\
\hline $\mathrm{N}$ category & 0.198 & 0.083 & & \\
\hline
\end{tabular}

Abbreviations: FBG: Fasting Blood Glucose; ALP: Alkaline Phosphatase; ALT: Alanine Aminotransferase; AST: Aspartate Aminotransferase; Hct: hematocrit; BUN: blood urea nitrogen. TNM classification is according to the International Union against Cancer (UICC, 2002). Multivariate regression analysis between betatrophin (dependent variable) and the independent variables shown. Standardized $\beta$ coefficients and $\mathrm{P}$ values are given. ${ }^{*}, \mathrm{p}<0.05$ is considered significant.

Table 4: Relationships between serum betatrophin levels and pancreatic cancer with various stages of glucose tolerance

\begin{tabular}{lcc}
\hline Covariates & OR $(\mathbf{9 5} \% \mathbf{C I})$ & P-value \\
\hline Betatrophin & $3.39(1.20-9.57)$ & $0.021^{*}$ \\
Amylase & $1.01(1.00-1.02)$ & $0.002^{*}$ \\
Lipase & $1.00(1.00-1.01)$ & 0.151 \\
CA 19-9 & $1.00(0.09-1.01)$ & 0.295 \\
Cholesterol & $0.97(0.95-0.98)$ & $<0.001^{*}$ \\
Triglyceride & $1.01(1.01-1.02)$ & $0.002^{*}$ \\
Hemoglobin & $0.63(0.48-0.82)$ & $0.001^{*}$ \\
ALP & $1.01(1.00-1.01)$ & $<0.001^{*}$ \\
ALT & $1.01(1.00-1.01)$ & $0.008^{*}$ \\
AST & $1.02(1.01-1.03)$ & $<0.001^{*}$ \\
\hline
\end{tabular}

Abbreviations: ALP: Alkaline Phosphatase; ALT: Alanine Aminotransferase; AST: Aspartate Aminotransferase. Insulin resistance classification: [Fasting Blood Glucose: Normal Glucose Tolerance (NGT) [ $\leq 99 \mathrm{mg} / \mathrm{dl} \mathrm{(5.5.} \mathrm{mmol/L)],}$ Impaired Glucose Tolerance (IGT) [100-125 mg/dl (5.6-6.9 mmol/L)], and Diabetes Mellitus (DM) [ $\geq 126 \mathrm{mg} /$ $\mathrm{dl}(7 \mathrm{mmol} / \mathrm{L})$. Ordinal logistic regression analysis between insulin resistance category (dependent variable) and the independent variables shown. $P$ values and OR $(95 \% \mathrm{CI})$ are given. ${ }^{*}$ Significant with $p<0.05$. 
A number of studies have showed that betatrophin levels were correlated with T1D and T2D and increased in T1D and T2D patients $[11,12,23,30]$. This increase may be related to increased insulin resistance and higher demand for insulin in T1D and T2D patients. Although the mechanisms underlying increased betatrophin levels in T1D and T2DM patients remain elusive, it is possible that liver and pancreas arise from a common multipotent population of endoderm and couple with the increased $\beta$-cell proliferation rate response to tissue-specific insulin resistance in the liver. Recently, Yi et al. [9] studies reported that hepatic expression of betatrophin was upregulated in mouse models of insulin resistance in which $\beta$-cell proliferation is increased. This model induced insulin resistance results in dramatic pancreatic $\beta$-cell proliferation. Indeed, overexpression of betatrophin by using adenovirus mediated method caused $\beta$-cell expansion and enhanced glucose clearance. These results suggest betatrophin to be a liver-derived protein that triggers compensatory $\beta$-cell proliferation upon insulin resistance. However, Gusarova et al. reported that overexpression of betatrophin in liver or knockout of betatrophin in mice does not alter beta cell expansion nor glucose metabolism when mice kept on a high fat diet (HFD) for 8 weeks [31]. Although this report provides contradictory evidence for a physiological role of betatrophin in the mouse $\beta$-cell function, the conclusion is far from conclusive. The normal glucose tolerance and glucose levels of the betatrophin $\mathrm{KO}$ mice suggest that betatrophin is not required physiologically for the maintenance of the $\beta$-cell mass. However, betatrophin (Angptl8) is an angiopoietin-like proteins family and 90\% homologous to Angptl3 and Angptl4 genes. Thus, it is possible to obscure the phenotype of the betatrophin $\mathrm{KO}$ mice due to a compensatory increase in homologous genes Angptl3 and Angptl4 levels. Indeed, Zhang et al. used the same insulin resistance model and found that betatrophin was significantly induced, whereas Angptl4 was suppressed [32]. Therefore, we speculate that the increase in serum betatrophin in PDAC-associated diabetes might be attributable to a defensive response, which may represent an ability to adapt to PDAC resulting in decline of $\beta$-cell proliferation rate and increased blood glucose concentrations. Indeed, plasma insulin levels of PDAC-DM patients were higher than in healthy subjects.

The present research study had a number of limitations. First, this study is limited by its cross-sectional design and provides no temporal interpretation of reported associations. Future studies should longitudinally evaluate the association between betatrophin levels and PDACassociated diabetes to better understand how betatrophin could alter normal glucose metabolism in PDAC patients and predict of PDAC-associated diabetes. Second, serum betatrophin levels were not an end point of recruited PDAC patients in the study, and measurements of serum betatrophin levels were made on stored samples, although the samples were relatively fresh. Third, our study is based on single measurement of serum betatrophin, which may not reflect betatrophin levels over time. Thus, serial changes in serum betatrophin in PDAC patients need to be measured to further clarify the role of betatrophin in the pathogenesis of PDAC-associated diabetes.

In summary, our results indicate for the first time that serum betatrophin levels were significantly correlated with PDAC-associated diabetes. The serum levels of betatrophin combined CA19-9 may serve as a potent biomarker for the early diagnosis of PDAC. Future studies are required to address the role of betatrophin in the pathogenesis of PDAC-associated diabetes.

\section{MATERIALS AND METHODS}

\section{Study population}

This case control study was approved by the institutional review board of the National Chiao Tung University, Taiwan. Eligible subjects were defined as 90 patients with PDAC who were admitted to the Taipei
A

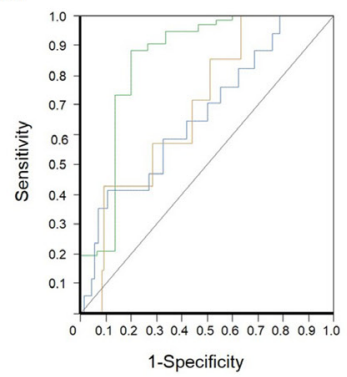

B

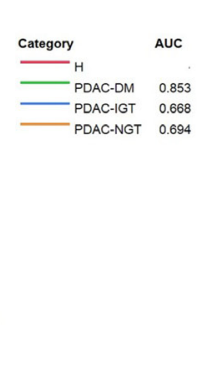

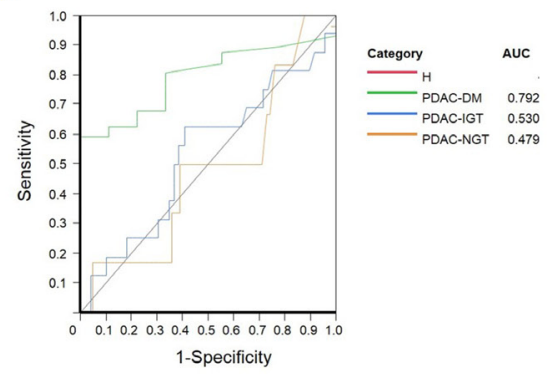

C

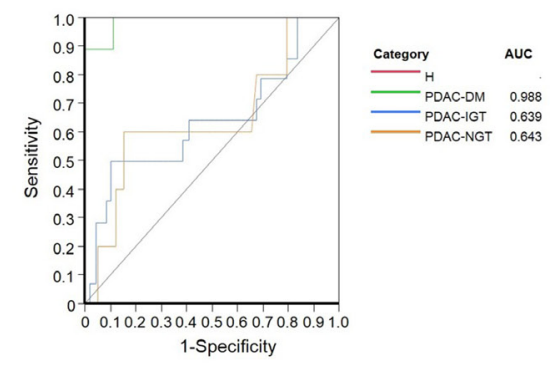

Figure 3: Receiver Operating Characterictic (ROC) curve analysis for betatrophin, CA 19-9, and betatrophin combined CA19-9 in pancreatic cancer-associated with diabetes (PC-DM), impaired glucose tolerance (PC-IGT), and non-diabetes (PC-NGT). A. ROC curve analysis for betatrophin in PC-DM and found that $\mathrm{AUC}_{\text {betatrophin }}$ is 0.853 ; B. ROC curve analysis for CA19-9 in PC-DM and found that $\mathrm{AUC}_{\mathrm{CA} 19-9}$ is 0.792 ; C. ROC curve analysis for betatrophin combined CA19-9 in PC-DM and found that $\mathrm{AUC}_{\text {betatrophin-CA19-9 }}$ is 0.988 . 
Veterans General Hospital, Taipei, Taiwan, between 1st January 2005 and 31st December 2012. The study protocol was performed according to the principles of the Declaration of Helsinki, and the written informed consent was obtained from all participants. Total 105 Taiwanese subjects are involved in this study. In brief, 15 healthy control subjects, and 12 patients having PDAC with normal glucose tolerance (PDAC-NGT), 12 patients having PDAC with impaired glucose tolerance (PDAC-IGT), and 66 patients having PDAC with diabetes mellitus (PDAC$\mathrm{DM})$ were enrolled for this study. Abdomen computerized tomography (CT) scan was used to confirm the patients with suspected for PDAC. Patients and controls were age from 60 to 75 years old. In addition, patients related to alcohol and tobacco consumption (e.g., respiratory diseases, peptic ulcer and hepatic disease) and had concurrent cancer at another organ site or past history of cancer were excluded. The control subjects were selected as subjects without disease and not taking any medications. Exclusion criteria were as follows: 1) any evidence of active infection (e.g. fever, or leukocytosis); 2) any evidence of impaired renal, hepatic, or hematopoietic function; 3) no known history of chronic systemic diseases, such as diabetes and hypertension; 4) no long-term medical treatment for chronic systemic diseases; 5) blood tests showing abnormal glucose levels. Moreover, normal glucose tolerance, impaired glucose tolerance and diabetes were diagnosed following the American Diabetes Association criteria: the study subjects were defined as having NGT if fasting blood glucose (FBG) value under 99 $\mathrm{mg} / \mathrm{dL}$ is NGT. IGT is between $100 \mathrm{mg} / \mathrm{dL}$ and $125 \mathrm{mg} / \mathrm{dL}$, and study subjects were defined as having diabetes if FBG value was $126 \mathrm{mg} / \mathrm{dL}$ or greater.

\section{Laboratory analysis}

Blood samples were collected after overnight fasting, and serum was stored at minus $20^{\circ} \mathrm{C}$. Serum variables were analyzed at the department of medical and chemical laboratory using routine procedures. The serum levels of betatrophin were quantified using a commercially available Enzyme Linked Immunosorbent Assay (ELISA) kit (Wuhan Eiaab Science, Wuhan, China; catalogue No. E11644h) according to the manufacturer's instructions [33]. Current ELISA kit was validated against other available kits showing correlation coefficient of 0.992 . Furthermore, the serum levels of CA 19-9 and insulin were quantified using ELISA) kit (IBL America, catalogue No. IB19124, Minneapolis, USA) and Human Insulin ELISA kit (Mercodia, Catalogue No. 10-1113-01, Sweden).

\section{Biochemical analyses}

Fasting glucose concentrations were measured by hexokinase method, triglyceride was assayed using standard enzymic method, and cholesterol was examined by cholesterol oxidase method. Moreover, albumin was determined by immuno-turbidmetric method. Creatinine was measured by Jaffe Reaction Method. All biochemical measurements were performed by Hitachi 7180E automatic biochemical analyzer (Hitachi Instruments Service, Tokyo, Japan). In addition, serum amylase/ lipase values were determined (LX-20; Beckman Coulter Fullerton, CA).

\section{Immunohistochemistry of betatrophin}

Immunohistochemistry of betatrophin was performed using surgical human specimens of PDAC. Briefly, paraffin sections were deparaffinized and incubated with methanol containing $0.3 \%$ hydrogen peroxide for $15 \mathrm{~min}$, then $10 \%$ normal goat serum (Jackson ImmunoResearch Inc., West Grove, PA, USA) was added to the sections to block non-specific staining. The sections were incubated with an anti-human betatrophin rabbit polyclonal antibody (1:400 dilution, GeneTex International Corporation, Hsinchu City, Taiwan) for $1 \mathrm{~h}$ at room temperature. After washing with PBS, sections were also incubated with the secondary antibody (rabbit IgG conjugated with horseradish peroxidase, (Jackson ImmunoResearch Inc., West Grove, PA, USA) for $40 \mathrm{~min}$ at room temperature. Sections were visualized by immersion in DAB (3,3 diaminobenzidine, Jackson ImmunoResearch Inc., West Grove, PA, USA) as a chromogen. Then nuclear staining was performed using hematoxylin, and each section was embedded.

\section{Statistical analysis}

All statistical analyses were performed using SPSS Software version 20.0 (IBM, Chicago, IL, USA). Differences in serum levels of betatrophin in healthy control subjects, PDAC-NGT, PDAC-IGT, and PDAC-DM patients were assessed by parametric one-way analysis of variance (ANOVA) with tukey post hoc test. Univariate correlations were performed using non-parametric Spearman's correlation test. Afterward, multivariate linear regression analysis was performed to identify independent relationships. Before univariate and multivariate analyses were calculated, the distribution of the respective variables was tested for normality using a Kolmogorov - Smirnov test. Univariate correlations were performed using parametric Pearson 's product moment method. Ordinal logistic regression analysis was performed to identify independent relationships. Area under the curve (AUC) were analyzed by ordinal logistic regression receiver operating characteristic (ROC) method with JMP 7.0 software (SAS Institute Inc, NC, USA). A P value less than 0.05 was considered statistically significant.

\section{ACKNOWLEDGMENTS}

We acknowledge and thank Dr. Guan-Hua Huang for helping in statistical analysis, and all participants for their cooperation and sample contributions. 


\section{CONFLICTS OF INTEREST}

All authors declare that they have no competing financial interest.

\section{GRANT SUPPORT}

This study was supported by grants 102-2320-B-009 -002 -MY3 and 104-2321-B-009 -001 from the Ministry of Science and Technology, Taiwan, Republic of China; "Aiming for the Top University Program" of the National Chiao Tung University and Ministry of Education, Taiwan, Republic of China. This work was also supported in part by the UST-UCSD International Center of Excellence in Advanced Bioengineering sponsored by the Ministry of Science and Technology I-RiCE Program under Grant Number: MOST 103-2911-I-009-101.

\section{Author contributions}

Chih-Hong Wang conceived the research and contributed to the research project design, the data interpretation and writing of the manuscript. Hendra Susanto, Ta-Yu Liu, and Chang-Chiang Chen contributed to participant recruiting, and analyzed the clinical data. Jerry D.T. Purnomo, and Shu-Fan Chen contributed to statistical analysis.

\section{REFERENCES}

1. Ryan DP, Hong TS, Bardeesy N. Pancreatic adenocarcinoma. N Engl J Med 2014; 371:1039-1049.

2. McDowell BD, Chapman CG, Smith BJ, Button AM, Chrischilles EA, Mezhir JJ. Pancreatectomy predicts improved survival for pancreatic adenocarcinoma: results of an instrumental variable analysis. Ann Surg 2015; 261:740-745.

3. Herman JM, Chang DT, Goodman KA, Dholakia AS, Raman SP, Hacker-Prietz A, Iacobuzio-Donahue CA, Griffith ME, Pawlik TM, Pai JS, O'Reilly E, Fisher G A, Wild A T, et al. Phase 2 multi-institutional trial evaluating gemcitabine and stereotactic body radiotherapy for patients with locally advanced unresectable pancreatic adenocarcinoma. Cancer 2015; 121:1128-1137.

4. Takahashi H, Akita H, Gotoh K, Kobayashi S, Marubashi S, Miyoshi N, Sugimura K, Motoori M, Kishi K, Noura S, Fujiwara Y, Ohue M, Ohigashi H. et al. Preoperative gemcitabine-based chemoradiation therapy for pancreatic ductal adenocarcinoma of the body and tail: impact of splenic vessels involvement on operative outcome and pattern of recurrence. Surgery 2015; 157:484-495.

5. Michaud DS. Epidemiology of pancreatic cancer. Minerva Chir 2004; 59:99-111.

6. Wang F, Herrington M, Larsson J, Permert J. The relationship between diabetes and pancreatic cancer. Mol Cancer 2003; 2:4.
7. Sikkens EC, Cahen DL, de Wit J, Looman CW, van Eijck $\mathrm{C}$, Bruno MJ. Prospective assessment of the influence of pancreatic cancer resection on exocrine pancreatic function. Br J Surg 2014; 101:109-113.

8. Raghow R. Betatrophin: A liver-derived hormone for the pancreatic beta-cell proliferation. World J Diabetes 2013; 4:234-237.

9. Yi P, Park JS, Melton DA. Betatrophin: a hormone that controls pancreatic beta cell proliferation. Cell 2013; 153:747-758.

10. Yamada H, Saito T, Aoki A, Asano T, Yoshida M, Ikoma A, Kusaka I, Toyoshima H, Kakei M, Ishikawa, SE. Circulating betatrophin is elevated in patients with type 1 and type 2 diabetes. Endocr J 2015.

11. Espes D, Lau J, Carlsson PO. Increased circulating levels of betatrophin in individuals with long-standing type 1 diabetes. Diabetologia 2014; 57:50-53.

12. Fu Z, Berhane F, Fite A, Seyoum B, Abou-Samra AB, Zhang R. Elevated circulating lipasin/betatrophin in human type 2 diabetes and obesity. Sci Rep 2014; 4:5013.

13. Zou L, Zhong R, Shen N, Chen W, Zhu B, Ke J, Lu X, Zhang T, Lou J, Wang Z, Liu L, Qi L, Miao X. Non-linear dose-response relationship between cigarette smoking and pancreatic cancer risk: evidence from a meta-analysis of 42 observational studies. Eur J Cancer 2014; 50:193-203.

14. Fenzl A, Itariu BK, Kosi L, Fritzer-Szekeres M, KautzkyWiller A, Stulnig TM, Kiefer FW. Circulating betatrophin correlates with atherogenic lipid profiles but not with glucose and insulin levels in insulin-resistant individuals. Diabetologia 2014; 57:1204-1208.

15. Locker GY, Hamilton S, Harris J, Jessup JM, Kemeny N, Macdonald JS, Somerfield MR, Hayes D F, Bast RC Jr. ASCO 2006 update of recommendations for the use of tumor markers in gastrointestinal cancer. J Clin Oncol 2006; 24:5313-5327.

16. Cui Y, Brosnan JA, Blackford AL, Sur S, Hruban RH, Kinzler KW, Vogelstein B, Maitra A, Diaz L A, Jr, Iacobuzio-Donahue C A, Eshleman JR. Genetically defined subsets of human pancreatic cancer show unique in vitro chemosensitivity. Clin Cancer Res 2012; 18:6519-6530.

17. Pannala R, Basu A, Petersen GM, Chari ST. New-onset diabetes: a potential clue to the early diagnosis of pancreatic cancer. Lancet Oncol 2009; 10:88-95.

18. Raghavan SR, Ballehaninna UK, Chamberlain RS. The impact of perioperative blood glucose levels on pancreatic cancer prognosis and surgical outcomes: an evidence-based review. Pancreas 2013; 42:1210-1217.

19. Aggarwal G, Ramachandran V, Javeed N, Arumugam T, Dutta S, Klee GG, Klee EW, Smyrk T C, Bamlet W, Han J J, Rumie Vittar NB, de Andrade M, Mukhopadhyay D. et al. Adrenomedullin is up-regulated in patients with pancreatic cancer and causes insulin resistance in beta cells and mice. Gastroenterology 2012; 143:1510-1517 e1511. 
20. Fogar P, Basso D, Panozzo MP, Del Favero G, Briani G, Fabris C, D'Angeli F, Meggiato T, Ferrara C, Plebani M.C-peptide pattern in patients with pancreatic cancer. Anticancer Res 1993; 13:2577-2580.

21. Stolzenberg-Solomon RZ, Graubard BI, Chari S, Limburg P, Taylor PR, Virtamo J, Albanes D. Insulin, glucose, insulin resistance, and pancreatic cancer in male smokers. JAMA 2005; 294:2872-2878.

22. Michaud DS, Wolpin B, Giovannucci E, Liu S, Cochrane B, Manson JE, Pollak MN, Ma J, Fuchs CS. Prediagnostic plasma C-peptide and pancreatic cancer risk in men and women. Cancer Epidemiol Biomarkers Prev 2007; 16:2101-2109.

23. Espes D, Martinell M, Carlsson PO. Increased circulating betatrophin concentrations in patients with type 2 diabetes. Int J Endocrinol 2014; 2014:323407.

24. seng YH, Yeh YH, Chen WJ, Lin KH. Emerging regulation and function of betatrophin. Int J Mol Sci 2014; 15:23640-23657.

25. Ahnfelt-Ronne J, Madsen OD. Betatrophin. Islets 2014; 6:e28686.

26. Shen CN, Horb ME, Slack JM, Tosh D. Transdifferentiation of pancreas to liver. Mech Dev 2003; 120:107-116.

27. Zaret KS. Genetic programming of liver and pancreas progenitors: lessons for stem-cell differentiation. Nat Rev Genet 2008; 9:329-340.
28. Horb ME, Shen CN, Tosh D, Slack JM. Experimental conversion of liver to pancreas. Curr Biol 2003; 13:105-115.

29. Barja-Fernandez S, Folgueira C, Seoane LM, Casanueva FF, Dieguez C, Castelao C, Aguera Z, Banos R, Botella C, de la Torre R, Fernandez-Garcia JC, Fernandez-Real JM, Fruhbeck G. et al. Circulating Betatrophin Levels Are Increased in Anorexia and Decreased in Morbidly Obese Women. J Clin Endocrinol Metab 2015; 100:E1188-1196.

30. Chen X, Lu P, He W, Zhang J, Liu L, Yang Y, Liu Z, Xie J, Shao S, Du T, Su X, Zhou X, Hu S, et al. Circulating betatrophin levels are increased in patients with type 2 diabetes and associated with insulin resistance. J Clin Endocrinol Metab 2015; 100:E96-100.

31. Gusarova V, Alexa CA, Na E, Stevis PE, Xin Y, BonnerWeir S, Cohen JC, Hobbs HH, Murphy AJ, Yancopoulos G D, Gromada J. ANGPTL8/betatrophin does not control pancreatic beta cell expansion. Cell 2014; 159:691-696.

32. Zhang R, Abou-Samra AB. A dual role of lipasin (betatrophin) in lipid metabolism and glucose homeostasis: consensus and controversy. Cardiovasc Diabetol 2014; 13:133.

33. Hu H, Sun W, Yu S, Hong X, Qian W, Tang B, Wang D, Yang L, Wang J, Mao C, Zhou L, Yuan G. Increased circulating levels of betatrophin in newly diagnosed type 2 diabetic patients. Diabetes Care 2014; 37:2718-2722. 